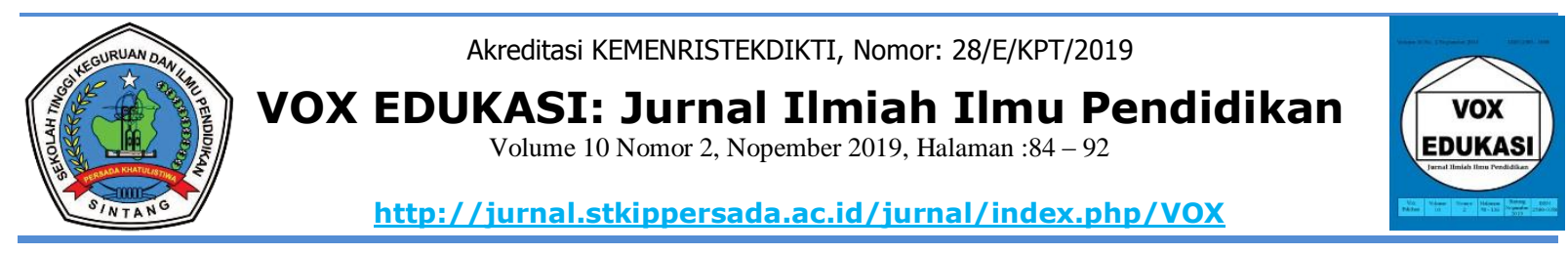

\title{
ANALISIS BAHASA DALAM MANTRA PENGOBATAN SAKIT PERUT SUBSUKU DAYAK DESA KABUPATEN SINTANG
}

\author{
Sudarto \& Adpriyadi \\ Program Studi Pendidikan Guru PAUD, STKIP Persada Khatulistiwa Sintang \\ Email: sudarto.niarto@gmail.com, adpriyadi@ymail.com,
}

\section{INFO ARTIKEL}

Riwayat Artikel:

Menerima : 25 September 2019

Revisi : : 16 Nopember 2019

Diterima : 29 Nopember 2019

\section{Kata Kunci:}

sastra lisan, suku dayak desa ensaid panjang

Keywords:

oral literature, long day village ensaid tribes

\section{Korespondensi:}

\section{Sudarto}

Program Studi Pendidikan Guru PAUD, STKIP Persada

Khatulistiwa Sintang

Email:

sudarto.niarto@gmail.com

\begin{abstract}
ABSTRAK
Masalah dalam penelitian ini adalah "Analisis Bahasa Mantra Pengobatan Sakit Perut Subsuku Dayak Desa Ensaid Panjang Kecamatan Kelam Permai Kabupaten Sintang. Penelitian ini bertujuan untuk mendeskripsikan jenis gaya bahasa, makna kata, dan lingkungan pembacaan mantra yang terdapat dalam Mantra Pengobatan Sakit Perut pada masyarakat Dayak Desa Ensaid Panjang Kecamatan Kelam Permai Kabupaten Sintang. Metode yang digunakan dalam penelitian ini adalah metode deskriptif, dengan pendekatan penelitian kualitatif dan pendekatan yang digunakan dalam penelitian ini adalah bentuk penelitian struktural semiotik. Teknik pengumpulan data yang digunakan dalam penelitian ini adalah teknik perekaman, pengamatan langsung, dan teknik wawancara bebas terarah. Hasil penelitian menunjukkan bahwa gaya bahasa yang terdapat dalam mantra pengobatan masyarakat Dayak Desa Ensaid Panjang meliputi: (1) gaya bahasa yang terdapat dalam mantra pengobatan masyarakat Dayak Desa Ensaid Panjang meliputi: (a) gaya bahsa pengulangan Aleterasi dan (b) gaya bahasa pengulangan kiasmus. (2) kata-kata yang terdapat dalam mantra berisikan permohonan agar penyakit yang diderita oleh seseorang dapat tersembuhkan (3) lingkungan pembacaan mantra pengobatan masyarakat Dayak Desa Ensaid Panjang tidak memiliki pantangan-pantangan, dalam melakukan pengobatan boleh kapan saja, hanya menyan yang harus ada dan yang lain boleh tidak ada. Penelitian ini dapat mengembangkan ilmu pengetahuan yang berkaitan dengan bahasa dan makna dalam sebuah mantra yang tergolong dalam puisi lama. Menjadi bahan pembelajaran terutama pembelajaran sastra khususnya sastra lama, yakni tentang makna, gaya bahasa, dan lingkungan pembacaan mantra yang terdapat dalam sebuah karya sastra
\end{abstract}

\section{ABSTRACT}

The problem in this study is "Spell Language Analysis of Sub-Dayak Stomach Pain Treatment in Ensaid Panjang Village, Kelam Permai District, Sintang Regency. Study aim at describing the type of language style, word meaning, and Mantra reading environment found in the Mantra Treatment of Stomachache in the Dayak Desa society of Ensaid Panjang Village, Kelam Permai District, Sintang Regency. The method used in this research is descriptive method, with a qualitative research approach and the approach used in this study is a form of semiotic structural research. Data collection techniques used in this study were recording techniques, direct observation, and directional free interview techniques. The results showed that the style of language contained in the Mantra treatment of the the Dayak Desa society of Ensaid Panjang Village consisted of: (1) the style of language contained in the Mantra treatment of the Dayak Village of the Ensaid Panjang Village included: (a) the style of Aleteration repetition (b) the style of the chiasmus repetition. (2) the words contained in the mantra requests that the illness suffered by a person can be cured (3) the environment for the recitation of the mantra of treatment for the Dayak Desa of Ensaid Panjang Village does not have restrictions, in doing the treatment may be at any time, there must an incense and the other is not necessary. This research can develop knowledge related to language and meaning in a mantra that is classified in old poetry. Become learning material, especially learning literature, especially old literature, which is about the 
meaning, style of language, and the spell reading environment contained in a literary work.

\section{PENDAHULUAN}

Bahasa merupakan sarana komunikasi utama yang digunakan oleh manusia untuk berinteraksi dan bersosialisasi dengan lingkungan sekitar dalam kehidupan sehari-hari. Bahasa yang digunakan merupakan medium atau sarana dalam berkomunikasi baik itu antar individu maupun individu dengan masyarakat. Melalui bahasa manusia dapat mengungkapkan pikiran dan perasannya. Kemajemukan sukusuku dapat kita jumpai pada setiap wilayah Indonesia satu di antaranya Kalimantan Barat. Banyak suku yang berdiam di Kaliamantan Barat, di antaranya suku Dayak.

Peneliti memilih bidang kajian sastra sebagai medium untuk meneliti masalah tersebut. Hal ini dikarenakan sastra memiliki hubungan yang sangat erat dengan kebudayaan. Sastra memiliki dua bidang kajian, yakni secara tertulis dan secara lisan. Sastra lisan merupakan pengekspresian dari nilai-nilai pendidikan, norma, dan agama suatu kelompok masyarakat tertentu yang disebarkan secara lisan. Sastra lisan juga dapat digunakan sebagai alat penghibur dan sebagai alat komunikasi.

Satu di antara sastra lisan itu adalah sastra lisan yang terdapat di Desa Ensaid Panjang. Sastra lisan yang terdapat pada masyarakat Dayak Desa banyak memiliki jenis dan bentuknya, beberapa diantaranya mantra, syair, dan pantun. Ada beberapa jenis mantra yang terdapat di daerah ini, diantaranya 1) mantra Pengobatan, 2) mantra Pengasih, dan 3) mantra menanam Padi. Pada penelitian ini peneliti membatasai pada mantra yang digunakan oleh masyarakat Dayak Desa Ensaid Panjang, untuk mengobati berbagai penyakit. Mantra ini dipercaya dapat menyembuhkan penyakit orang yang terkena penyakit.

Adapun mantra yang dipilih, yakni 1) Mantra Pengobatan Demam Panas, 2) Mantra Pengobatan Anak Rewel, dan 3) Mantra Pengobatan Sakit Perut. Alasan peneliti memilih ketiga mantra tersebut, karena: 1) peneliti menganggap bahwa ritual pengobatan sangat penting karena menyangkut pada keadaan lahir dan batin seseorang, dengan demikian peneliti ingin mengetahui seperti apa ritual yang dilakukan dan seperti apa mantra yang digunakan, 2) peneliti ingin mengetahui bahasa mantra khususnya pada kata-kata yang terdapat dalam mantra-mantra tersebut, 3) peneliti juga ingin mengetahui hal apa yang menyebabkan masyarakat Dayak Desa Ensaid Panjang sangat mempercayai bahwa mantramantra tersebut dapat mengobati penyakit yang diderita oleh seseorang, 4) peneliti juga tertarik memilih ketiga mantra tersebut karena pada saat peneliti melakukan prariset, peneliti melihat hampir setiap orang yang minta diobat 
selalu terkena penyakit-penyakit tersebut, 5) peneliti ingin mempublikasikan kepada masyarakat tentang sebuah sastra yang ada pada masyarakat Dayak Desa Ensaid Panjang, 6) peneliti ingin mengetahui bagaimana makna kata-kata yang terdapat dalam mantra tersebut yang dianggap masyarakat Dayak Desa Ensaid Panjang dapat mengobati penyakit yang diderita, 7) karena mantra tersebut hanya diketahui oleh orang-orang tertentu saja, seperti dukun dan tetua kampung, dan 8) mantramantra pengobatan ini semakin jarang digunakan sehingga mantra ini harus dilestarikan.

Hotomo (Yusuf, 2009: 23) sastra lisan adalah kesusatraan yang mencakup ekspresi kesusastraan warga suatu kebudayaan yang disebarkan dan diturunkan secara lisan, bersifat komunal, terdiri dari berbagai versi, serta tidak mementingkan fakta dan kebenaran. Jika dilihat dari segi pengertiannya, sastra lisan dapat dibagi dua jenis, yakni: 1) sastra lisan yang bernilai sastra dan 2) sastra lisan yang tidak bernilai sastra. Jenis pertama umumnya dituturkan oleh para penutur professional, misalnya tukang kaba (Minangkabau), penglipur lara (Melayu), Jemplung (Jawa), dan lain-lain. Jenis kedua dituturkan oleh orangorang biasa yang kebetulan dapat menceritakannya.

Sebagai ilmu gabung, maka ia lebih merupakan penjumlahan antara linguistik dan sastra (Yunus, 2003: 160 ). Dengan demikian, baik linguistik maupun sastra masing-masing dapat mengklaim bahwa stilistika adalah miliknya: Hakikat stilistika sebagai ilmu menjadi sulit perwujudannya. Edaswara (2003: 151) menyatakan bahwa ciri-ciri sastra lisan, yakni: (1) lahir dari masyarakat yang polos, belum melek huruf, dan bersifat tradisional; (2) menggambarkan budaya milik kolektif tertentu, yang tidak jelas siapa penciptanya; (3) lebih menekan kan aspek khayalan, ada sindiran, jenaka, dan pesan mendidik; (4) sering melukiskan tradisi kolektif tertentu.

Piah (Yusuf, 2009: 27) menyatakan bahwa dari segi isinya, mantra Melayu dapat dibagi ke dalam empat bagian penting, yaitu: 1) pakaian diri (jenis tangkal atau jimat), 2) medium dalam permohonan dan pengobatan, 3) sayarat dalam upacara adat, dan pembantu dalam usaha pengobatan. Hal ini sesuai dengan pendapat Syam (2010: 43) mengatakan bahwa ada beberapa contoh mantra yang biasa digunakan, yakni mantra pengobatan, mantra pengasih, dan mantra pelindung.

Martono (2008: 19) menyatakan bahwa gaya bahasa dapat diklasifikasikan menjadi: gaya bahasa pertentangan, gaya bahasa perbandingan, gaya bahasa pertautan, dan gaya bahasa perulangan. Metonimia adalah majas yang berupa pemakaian nama ciri atau nama hal yang dikaitkan dengan barang. Hal ini sesuai dengan pendapat Martono (2008: 35) menyatakan bahwa metonimia adalah gaya bahasa yang dipergunakan untuk mengganti nama, yakni berupa atribut sebuah objek atau penggunaan 
sesuatu yang sangat dekat dengan objek yang di gantikan.

Kehadiran mantra di dalam sejumlah aktivitas dan kepentingan masyarakat di suatu wilayah, misalnya, dapat diidentifikasi sebagai tanda yang memiliki hubungan erat dengan kultur yang membentuknya. Situasi awal cerita menggambarkan keadaan sebelum ada suatu peristiwa yang menggangu keseimbangan harmoni. Konteks penceritaan meliputi lingkungan penceritaan serta situasi penceritaan. Lingkungan penceritaan, seperti dijelaskan oleh Yus (Only, 2007: 22). Pembahasan mengenai unsur-unsur berikut a) penutur cerita, b) kesempatan bercerita, c) tujuan bercerita, dan d) hubungan cerita dengan lingkungannya.

\section{METODE PELAKSANAAN}

Metode yang digunakan dalam penelitian ini adalah metode deskriptif. Sejalan dengan penjelasan tersebut, Subana dan Sudrajat (2005: 89) menyatakan bahwa penelitian deskriptif menuturkan dan menafsirkan data yang berkenaan dengan fakta, keadaan, dan fenomena yang terjadi saat penelitian berlangsung dan menyajikannya apa adanya. Nawawi (2005: 63) menyatakan bahwa metode deskriptif diartikan sebagai prosedur pemecahan masalah yang diselidiki dengan menggambarkan/melukiskan keadaan subjek/objek penelitian (seseorang, lembaga, Masyarakat, dan lain-lain) pada saat sekarang berdasarkan fakta-fakta yang tampak atau sebagaimana adanya.

Teknik pengumpulan data yang digunakan dalam penelitian ini sebagai berikut; (1) observasi langsung ke lapangan, (2) wawancara langsung kepada informan, (3) merekam mantra pengobatan dari informan, (4) Mentranskripsikan rekaman dari bentuk lisan ke dalam teks tertulis, (5) Menerjemahkan data dari bahasa aslinya ke bahasa Indonesia.

Teknik analisis data yang digunakan dalam penelitian ini adalah deskriptif kualitatif. Melalui teknik ini peneliti mendeskripsikan hasil penelitian. Langkah-langkah yang digunakan dalam menganalisis data sebagai berikut; (1) membaca teks mantra secara intensif dan berulang-ulang, (2) mengidentifkasi dan mengklasifikasikan data-data berdasarkan gaya bahasa, makna, dan lingkungan pembacaan mantra yang terdapat dalam mantra pengobatan masyarakat Dayak Desa Ensaid Panjang Kecamatan Kelam Permai Kabupaten Sintang, (3) menafsirkan dan mendeskripsikan data-data yang telah diklasifikan setelah memberikan penafsiran dan melakukan pendiskripsian terhadap data-data, peneliti akan memberikan simpulan terhadap hasil analisis data sesuai dengan masalah yang terdapat dalam penelitian ini, dan 4) setelah memberikan penafsiran dan 
melakukan pendiskripsian terhadap datadata, peneliti akan memberikan simpulan terhadap hasil analisis data sesuai dengan masalah yang terdapat dalam penelitian ini.

\section{HASIL DAN PEMBAHASAN}

Pada penelitian ini, teknik analisis data ada tiga bagian yaitu analisis gaya bahasa mantra, makna bahasa mantra, dan lingkungan pembacaan mantra. Analisis mantra pengobatan ini peneliti menggunakan bagian-bagian pembacaan yang disingkat, yaitu mantra sakit perut yang disingkat MSP.

Gaya bahasa yang terdapat dalam Mantra Pengobatan sakit perut pada masyarakat Dayak Desa Ensaid Panjang Kecamatan Kelam Permai Kabupaten Sintang dianalisis berdasarkan gaya bahasa pengulangan aleterasi. Mantra pengobatan Sakit Perut (Ribu Atau Batu, Kulat Gelang Tumuh Dibatang, Isau Kenu Antu, Kayu Kenu Aku, Kujur Kenu Antu, Kayu Kenu Aku, Bisa Kenu Aku, Tabar Kenu Antu, Mungah Merubah Tawar, Asal Temula Jadi, Lah Tabarhlah).

Adapun aleterasi yang terdapat dalam mantra pengobatan sakit perut adalah pada baris ke- 2 yakni pada kata "Kulat Gelang Tumuh Dibatang". Gaya bahasa pengulangan kiasmus yang terdapat dalam mantra pengobatan sakit perut adalah baris ke-1, 3-11 yakni pada kata frase "Ribu Atau Batu;Isau Kenu Antu, Kayu Kenu Aku, Kujur Kenu Antu, Kayu Kenu Aku, Bisa Kenu Aku, Tabar Kenu Antu, Mungah Merubah Tawar, Asal Temula Jadi, Lah Tabarhlah".

Mantra Pengobatan sakit perut pada masyarakat Dayak Desa Ensaid Panjang Kecamatan Kelam Permai Kabupaten Sintang dianalisis berdasarkan makna pembaca Heuristik mantra pengobatan sakit perut. Mantra Pengobatan Sakit Perut, Ribu Atau Batu (ribu di atas batu), Kulat Gelang Tumuh Dibatang (jamur gelang tumbuh di batang kayu), Isau Kenu Antu (pisau kata hantu), Kayu Kenu Aku (kayu kata aku), Kujur Kenu Antu (tombak kata hantu), Кауи Кепи Aku (Кауи kata aku), Bisa Kenu Aku (mampu kata aku,Tabar Kenu Antu (netralkan punya hantu), Mungah Merubah Tawar (tokoh sesepuh dayak), Asal Temula Jadi (asal muasal), Lah Tabarhlah (netralkanlah).

Lingkungan yang terdapat dalam Mantra Pengobatan sakit perut pada masyarakat Dayak Desa Ensaid Panjang Kecamatan Kelam Permai Kabupaten Sintang. Pengobatan adalah suatu usaha untuk menyembuhkan suatu penyakit. Dalam menyembuhkan penyakit masyarakat Dayak Desa Ensaid Panjang Kecamatan Kelam Permai Kabupaten 
Sintang memiliki berbagai alternatif yang satu diantaranya dengan melakukan pengobatan tradisional yang dilakukan oleh seorang dukun. Proses pengobatan yang dilakukan ada yang memiliki perturanperaturan atau pantangan-pantangan yang harus dipatuhi oleh si dukun, orang yang ikut menyaksikan, dan orang yang diobati. Pantangan tersebut bergantung sesuai dengan jenis penyakit. Untuk penyakit yang peneliti teliti tidak meiliki pantanganpantangan yang harus dipatuhi.

Berdasarkan wawancara peneliti dengan informan mengenai keadaan dan suasana pelaksanaan proses pengobatan dapat dijelaskan bahwa untuk pengobatan demam panas, anak rewel, dan sakit perut tidak terdapat pantangan-pantangan. Hal tersebut dikarenakan penyakit-penyakit tersebut tidak menggunakan perabahan yang banyak, penyakit tersebut tergolong penyakit yang masih ringan, dan pengobatan penyakit Sakit Perut tidak menggunakan ritual yang besar.

Situasi pengobatan penyakit Sakit Perut boleh dilihat dan disaksikan oleh siapapun. Pada proses pengobatan biasanya banyak orang-orang tua yang datang untuk menyaksikan, dengan demikian suasana akan menjadi agak ramai. Hal demikian tidak mengganggu berlangsungnya ritual. Dalam melakukan ritual sidukun tidak bekerja sendiri.
Biasanya ia dibantu oleh orang lain yang telah mengerti proses pengobatan. Orang yang membantu biasanya adalah seorang wanita yang sudah tua dan biasanya ia bertugas untuk menyembur sirih, kunyit, kapur sirih dan garam mengarahkan si sakit agar mengikuti apa yang diinginkan oleh si dukun.

Waktu pengobatan penyakit SP boleh dilakukan kapan saja tidak harus ditentukan, jika ditentukan hanya memberikan waktu kepada keluarga si sakit untuk mencari dan membuat bahan-bahan yang digunakan untuk pengobatan.

Biasanya dalam mengobati sakit perut masyarakat dayak Desa Ensaid Panjang Kecamatan Kelam Permai Kabupaten Sintang melaksanakannya pada saat sore hari. Ini dikarenakan ada hal-hal yang dipertimbangkan, pagi hari si dukun masih melakukan aktivitas yang lain, misalnya pergi ke ladang dan menjelang sore baru kembali ke rumahnya dan waktu pagi hingga siang digunakan keluarga si sakit untuk mencari dan membuat barangbarang perabahan. Menjelang sore baru kegiatan dilakukan, hal tersebut dikarenakan di waktu sore cuaca sudah tidak terlalu panas.

Yusuf (2009: 27) menyatakan bahwa dari segi isinya, mantra Melayu dapat dibagi ke dalam empat bagian penting, 
yaitu: 1) pakaian diri (jenis tangkal atau jimat), 2) medium dalam permohonan dan pengobatan, 3) sayarat dalam upacara adat, dan pembantu dalam usaha pengobatan. Hal ini sesuai dengan pendapat Syam (2010: 43) mengatakan bahwa ada beberapa contoh mantra yang biasa digunakan, yakni mantra pengobatan, mantra pengasih, mantra pelindung.

Martono (2008: 19) menyatakan bahwa gaya bahasa dapat diklasifikasikan menjadi: gaya bahasa pertentangan, gaya bahasa perbandingan, gaya bahasa pertautan, dan gaya bahasa perulangan. Gaya bahasa yang terdapat dalam Mantra Pengobatan sakit perut pada masyarakat Dayak Desa Ensaid Panjang Kecamatan Kelam Permai Kabupaten Sintang dianalisis berdasarkan gaya bahasa pengulangan aleterasi dan Gaya bahasa kiasmus.

Gaya bahasa aleterasi yang terdapat dalam mantra pengobatan sakit perut adalah pada baris ke- 2 yakni pada kata "Kulat Gelang Tumuh Dibatang.

Gaya bahasa kiasmus yang terdapat dalam mantra pengobatan sakit perut adalah baris ke-1, 3-11 yakni pada kata frase "Ribu Atau Batu; Isau Kenu Antu, Kayu Kenu Aku, Kujur Kenu Antu, Kayи Kenu Aku, Bisa Kenu Aku, Tabar Kenu Antu, Mungah Merubah Tawar, Asal Temula Jadi, Lah Tabarhlah
Makna kata sangat berkaitan dengan perbendaharaan kata yang digunakan. Kata yang digunakan harus mengandung dua aspek, yaitu aspek bentuk dan aspek isi. Kata sebagai satuan dari perbendaharaan kata sebuah bahasa mengandung dua aspek, yaitu aspek bentuk atau ekspresi dan aspek isi makna (Keraf, 2006: 25). Hawkey (Pradopo, 2003: 93-94) menyatakan bahwa makna unsur-unsur karya sastra itu hanya dapat dipahami dan dinilai sepenuhnya atas dasar pemahaman tempat dan fungsi unsur itu dalam keseluruhan karya sastra.

Mantra Pengobatan sakit perut pada masyarakat Dayak Desa Ensaid Panjang Kecamatan Kelam Permai Kabupaten Sintang dianalisis berdasarkan makna pembaca Heuristik mantra pengobatan sakit perut. Mantra Pengobatan Sakit Perut, Ribu Atau Batu (ribu di atas batu), Kulat Gelang Tumuh Dibatang (jamur gelang tumbuh di batang kayu), Isau Kenu Antu (pisau kata hantu), Kayu Kenu Aku (kayu kata aku), Kujur Kenu Antu (tombak kata hantu), Kayu Kenu Aku (Kayu kata aku), Bisa Kenu Aku (mampu kata aku,Tabar Kenu Antu (netralkan punya hantu),Mungah Merubah Tawar (tokoh sesepuh dayak), Asal Temula Jadi (asal muasal), Lah Tabarhlah (netralkanlah).

Kehadiran mantra di dalam sejumlah aktivitas dan kepentingan 
masyarakat di suatu wilayah, misalnya, dapat diidentifikasi sebagai tanda yang memiliki hubungan erat dengan kultur yang membentuknya. Situasi awal cerita menggambarkan keadaan sebelum ada suatu peristiwa yang menggangu keseimbangan harmoni (Only, 2007: 2). Konteks penceritaan meliputi lingkungan penceritaan serta situasi penceritaan. Lingkungan penceritaan, seperti dijelaskan oleh Yus (Only, 007: 22). Pembahasan mengenai unsur-unsur berikut a) penutur cerita, b) kesempatan bercerita, c) tujuan bercerita, dan d) hubungan cerita dengan lingkungannya.

Lingkungan yang terdapat dalam Mantra Pengobatan sakit perut pada masyarakat Dayak Desa Ensaid Panjang Kecamatan Kelam Permai Kabupaten Sintang tidak memerlukan waktu yang khusus, tidak terdapat pantangan-pantangan yang begitu mengikat.

\section{SIMPULAN}

Berdasarkan hasil penelitian dan penganalisisan terhadap bahasa dalam mantra pengobatan masyarakat Dayak Desa Ensaid Panjang Kecamatan Kelam Permai Kabupaten Sintang dapat ditarik kesimpulan sebagai berikut; (1) Gaya bahasa yang terdapat dalam mantra pengobatan sakit perut adalah gaya bahasa Pengulangan yakni aliterasi, dan kiasmus. (2) Makna kata yang terdapat dalam mantra pengobatan sakit perut berisikan permintaan dan permohonan kepada sang pencipta agar kegiatan yang dilaksanakan dapat berlangsung dengan lancar dan mendapatkan hasil yang baik. Selain itu, juga mengajarkan bahwa untuk melakukan sesuatu kita haruslah meminta pertolongan kepada Tuhan. (3) Lingkungan pembacaan mantra pengobatan khususnya penyakit sakit perut tidak memerlukan waktu yang khusus, tidak terdapat pantangan-pantangan yang begitu mengikat, dan perabahan yang digunakan boleh ada dan boleh tidak kecuali menyan.

\section{UCAPAN TERIMA KASIH}

Ucapan terima kasih dan penghargaan penulis sampaikan kepada: (1) Direktorat Riset dan Pengabdian Masyarakat, Direktorat Jenderal Penguatan Riset dan Pengembangan, Kementrian Riset, Teknologi, dan Pendidikan Tinggi yang telah memberikan bantuan Dana Hibah Penelitian Dosen Pemula sehingga penulis dapat menyelesaikan Penelitian Dosen Pemula ini. (2) Dr. Drs. Y. A. T. Lukman Riberu, M.Si selaku Ketua Perkumpulan Badan Pendidikan Karya Bangsa Sintang yang telah memberikan dukungan moriil sehingga penulis dapat menyelesaikan Penelitian Dosen Pemula ini. (3) Drs. Rafael Suban Beding, M.Si selaku ketua Sekolah Tinggi Keguruan dan Ilmu Pendidikan Persada Khatulistiwa Sintang yang telah memberikan dukungan moriil sehingga penulis dapat menyelesaikan Penelitian Dosen Pemula ini. (4) Bapak/ibu dosen atas doa, keramahan, dan kerja samanya dalam pelaksanaan penelitian sehingga penulis dapat menyelesaikan Penelitian Dosen Pemula ini. 
(5) Bapak/ibu pemantra Dayak Desa Ensaid Panjang Kecamatan Kelam Permai Kabupaten Sintang atas kerjasamanya dalam pelaksanan Penelitian Dosen Pemula.

\section{REFERENSI}

Yunus, Umar. 2003. Stilistika Suatu Pengantar. Kuala Lumpur: Dewan Bahasa dan Pustaka Kementerian Pendidikan Malaysia.

Endraswara, Suwardi. 2003. Metodologi Penelitian Sastra Epistemologi, Model, Teori, dan Aplikasi. Yogyakarta: CAPS.

Keraf, Goris. 2006. Diksi dan Gaya Bahasa. Jakarta: Gramedia

Martono 2001. Sikap Hidup Orang Dayak Keninjal dalam Sastra Lisan Dayak Keninjal. (Tesis). Universitas Negeri Malang.

Nauman, Indra Jaya. 2001. Penuntun Mengenali, Memahami, dan Menghargai Puisi. Yogyakarta: Adicita Karya Nusa.
Nawawi, Hadari. Metodelogi Penelitian Bidang Sosial. Pontianak: Gadjah Mada University Press.

Pradopo, Rachmat Djoko. 2001. Pengkajian Puisi. Yogyakarta: Gajah Mada University Press

Syam, Cristanto. 2010. Pengantar ke Arah Studi Sastra Daerah. Buku Ajar. Pontianak: Universitas Tanjungpura

Subana dan Sudrajat. 2005. Dasar-Dasar Penelitian Ilmiah. Bandung: Pustaka Setia.

The Only. one. 2007. [Online].(http://theonlywann. blogspot.com/2007/11/bab-2. $\quad \mathrm{html}$ dikunjungi 20 April 2017).

Yusuf, Muhammad, 2009. "Nilai Religi dalam Mantra Menanam Padi masyarakat Melayu Desa Padu Banjar Kabupaten Kayong Utara (Skripsi)". Pontianak: FKIP Universitas Tanjungpura. 